\title{
POST PCI VASCULAR AND BLEEDING COMPLICATIONS IN PATIENTS WITH OR WITHOUT CKD
}

\author{
Harish Oruganti ${ }^{1}$, Jyotsna Maddury²
}

\section{ABSTRACT}

BACKGROUND: There is increasing trend of both Cardiovascular disease (CVD) and chronic kidney diseases $(C K D)$ in general populations. The individuals with CKD are more likely to die of CVD than of kidney failure. Both diagnostic and therapeutic interventions are crucial in management of CKD patients with coronary artery disease. As CKD itself is associated with more bleeding complications we aim to study the incidence of vascular complications (vessel thrombosis, distal embolisation, dissection, poorly controlled bleeding at puncture site, pseudoaneurysm, arteriovenous fistula, retroperitoneal hematoma, and development of femoral neuropathy) in Percutaneous intervention (PCI) patients with renal failure.

METHODS: 950 patients who underwent PCI procedures were classified into CKD (GFR $<60 \mathrm{ml} / \mathrm{min} / \mathrm{m} 2)(n=380,40 \%)$ and nonCKD (n=570,60\%) groups. Two groups were analyzed for the occurrence of vascular complications post PCI.

RESULTS: Vascular complications were seen in 28 out of 380 patients with CKD (7.37\%) and 17 out of 570 patients without CKD (2.98\%). Patients with renal failure (GFR $<60 \mathrm{ml} / \mathrm{min} / \mathrm{m} 2)$ were found to have higher risk of vascular complications post PCI. $[p=0.03$, OR $=2.588(1.344-5.017)]$. Non access site complications were more common in patients with CKD compared to non CKD.16 patients with CKD developed non access site complications compared to 9 in patients without CKD.[p=0.001,odds ratio 2.793(1.15-6.916)

CONCLUSIONS: This study demonstrates higher risk of vascular complications post-PCI in patients with CKD compared to non CKD patients. Higher incidence of non access site complications was also observed in CKD patients.

KEY WORDS : vascular complication, glomerular filtration rate, non-access site bleed

Article received on 5 Jan 2016, published on 25 JAN 2016.

Harish Oruganti ${ }^{1}$, Jyotsna Maddury ${ }^{2}$

${ }^{1}$ Senior resident, Departments of Cardiology, NIMS, India

${ }^{2}$ Professor \& HOU-IV

Corresponding author: Harish Oruganti

Email: harishoruganti@gmail.com

\section{INTRODUCTION}

Chronic kidney disease (CKD) is increasing in incidence, as is cardiovascular disease. Both carry large risks of major morbidity and mortality. The interaction of these two conditions is complex and the addition of CKD to cardiovascular disease worsens the long term prognosis in the latter [1]. Percutaneous intervention (PCI) for obstructive CAD is technically feasible in CKD patients. But PCI did not ameliorate the increased morbidity and mortality associated with CKD and certain procedural complications like access site complications, major bleeding and contrast nephropathy were actually increased in these patients compared to non-CKD patients [2, 3].

Vascular and bleeding complications are known to occur after PCI. These range from pseudo-aneurysm, arterial occlusion, local access site bleed, GI bleed, intraocular, intracranial and retroperitoneal bleed. In this study we tried to analyze the influence of CKD on the occurrence of post-PCI vascular and bleeding complications.

\section{MATERIALS AND METHODS:}

STUDY POPULATION: We retrospectively analyzed the obstructive CAD patients who underwent PCI in our institution which is a high volume center between January to august 2013. The patients who underwent PCI both elective and emergency were included in this study. Patients who needed intra-aortic balloon counter pulsation and larger coronary devices like atherectomy device or rotablator were excluded from the study.

DATA COLLECTION: Demographic and clinical data on age, gender, smoking habit, diabetes mellitus (DM), and hypertension were obtained via review of patient medical case sheets. Body mass index (BMI) was measured by weight and height of patient and expressed as $\mathrm{kg} / \mathrm{m} 2$. All blood examinations including total cholesterol, triglycerides, high density lipoprotein 
(HDL) cholesterol, low density lipoprotein (LDL) cholesterol, fasting blood glucose (FBG), creatinine, hemoglobin were measured after an overnight fast of at least $12 \mathrm{hr}$. Serum creatinine was measured by enzymatic method.

All the patients underwent PCI with uniform sheath size of $6 \mathrm{~F}$. All the patients enrolled in the study were given $325 \mathrm{mg}$ aspirin and clopidogrel $600 \mathrm{mg}$ or prasugrel 60 $\mathrm{mg}$ loading dose independent of their previous antiplatelet intake status to attain therapeutic drug levels and blood sample for platelet inhibition was collected 2 hours later. Anticoagulation is done with weight adjusted standard dose unfractionated heparin (100 units/kg body weight) bolus. Sheath removal and compression was done manually in all patients by trained cath-lab personnel.

DEFINITIONS: CKD was defined as baseline GFR $<60 / \mathrm{mL} / \mathrm{min}$ as calculated by the Cockcroft-Gault formula: $(140$-age $) \times($ weight $)(\times 0.85$ if female $) /(72 \times$ serum creatinine). This formula has been validated and accurately predicts the glomerular filtration rate[4].

Vascular complications: Only the outcomes that occurred in hospital were included in the analyses. They include one or more of the following: access site (hematoma, pseudo-aneurysm), non-access site (retroperitoneal, genitourinary, gastrointestinal, intracranial) hemorrhage. Bleeding Academic Research Consortium Definition for bleeding[5] was adopted in our study. Large local hematoma is defined as $>10 \mathrm{~cm}$ size of blood collection with femoral access, $>2 \mathrm{~cm}$ with radial access, or $>5 \mathrm{~cm}$ with brachial access. Pseudoaneurysm is defined as the occurrence of a disruption and dilation of the arterial wall without identification of the arterial wall layers at the site of the catheter entry demonstrated by arteriography or ultrasound.

STATISTICAL ANALYSIS: Baseline characteristics were compared between patients with CKD to patients without CKD. Continuous variables were expressed as the mean \pm standard deviation (SD) and compared using an unpaired two-sided Student's t-test when normal distribution and equal dispersion were confirmed. Categorical variables were expressed as percentages (\%) and compared using chi-square analysis . A multiple logistic regression analysis was performed to correlate eGFR with other variables (age ,weight ,height, hemoglobin, platelet count). A p-value of less than 0.05 was considered statistically significant. All statistical analyses were performed with MINITAB (version 17.0 for Windows).

\section{RESULTS:}

950 eligible patients who underwent PCI procedures were included in the study. M:F::3.4:1 with age ranging between 18 to 89 yrs. Out of 950 total patients, 215 were females with mean age of 55.4+_10.5years. Demographic details were given in Table 1 \& Fig 1.

Table 1 : Demographic details of all study patients.

\begin{tabular}{|l|l|}
\hline Variables & Results \\
\hline Total No. of cases & 950 \\
\hline Females & 215 \\
\hline Age $(\mathrm{yrs})$ & $55.4 \pm 10.5$ \\
\hline Hemoglobin $(\mathrm{g} / \mathrm{dl})$ & $12.9 \pm 2$ \\
\hline Platelet count $(\mathrm{lakhs} / \mathrm{dl})$ & $2.4 \pm 0.8$ \\
\hline eGFR $\left(\mathrm{ml} / \mathrm{min} / 1.73 \mathrm{~m}^{2}\right)$ & $72.02 \pm 50.84$ \\
\hline
\end{tabular}

Fig 1 : Individual plots representing the age, weight, height, estimated Glomerular Filtration Rate, Hemoglobin and platelet count of all patients.

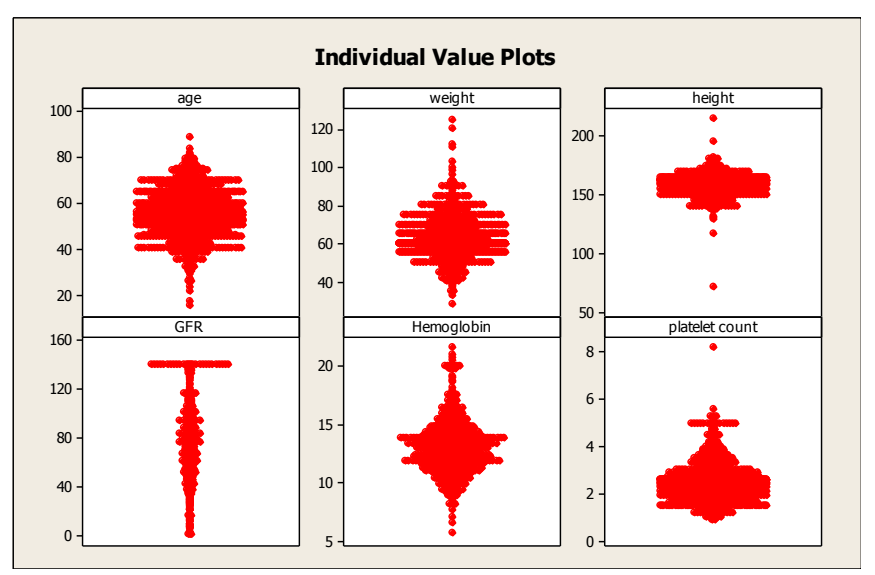

There was small correlation of eGFR \& age $(r=0.13, p=$ $0.00)$ and hemoglobin $(r=0.14, p=0.00)$. 3D scatter plot of eGFR vs age vs height (Fig 2) and surface plot of eGFR vs age, hemoglobin (Fig 3) of the study population shows that older age group is associated with decrease eGFR. 
Fig 2: 3D scatter plot of eGFR vs age vs height.

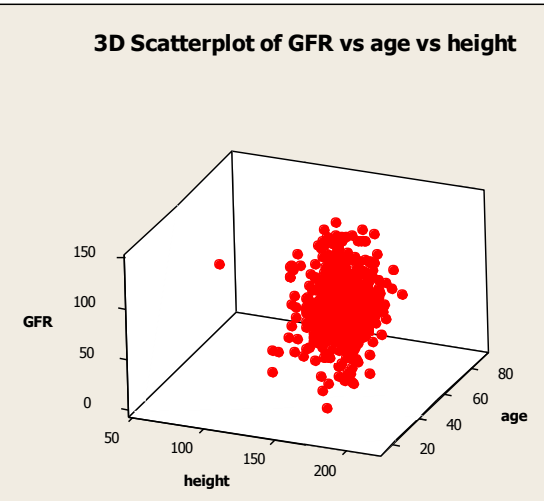

Fig 3 : Surface plot of eGFR vs age, hemoglobin

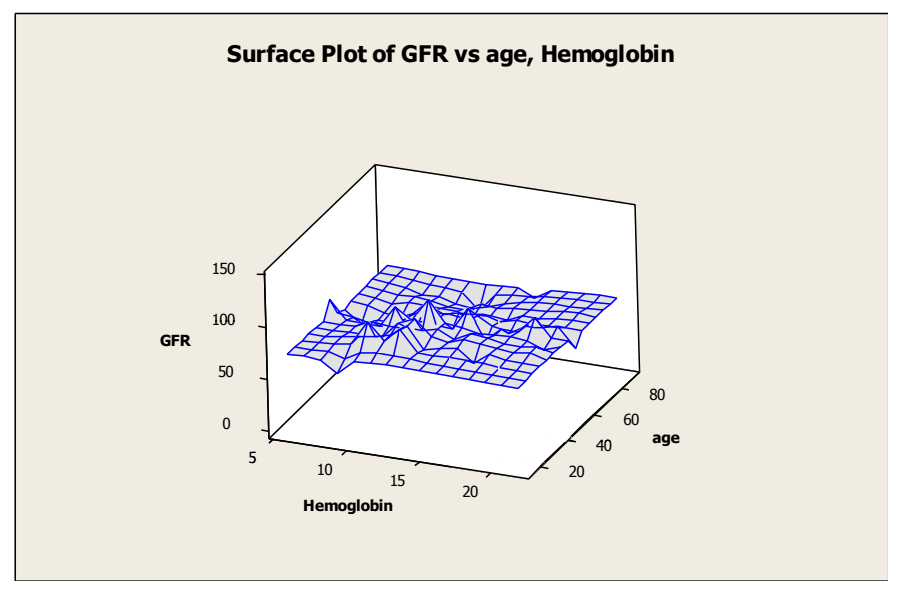

This study population of 950 patients were classified into CKD group $(\mathrm{n}=380,40 \%)$ and non-CKD groups ( $\mathrm{n}$ $=570,60 \%)$. Baseline demographic and clinical characteristics are given in the Table 2 and Fig 4.

CKD patients were slightly older, less BMI, anemic than Non- CKD patients. As the all patients were taken up with prior treatment there was no difference in total cholesterol and systolic BP.

Table 3 is showing the details of PCI. Total number of lesions in CKD and non CKD groups: Total no of lesions treated in 950 patients were 1243.

Multi-vessel angioplasty and radial route were done more frequently in non-CKD compared with CKD patients with a significant $p$ value as shown in Table 4 and Fig 4.
Table 2: Demographic and clinical characteristics of study population

\begin{tabular}{|l|l|l|l|}
\hline Variables & $\begin{array}{l}\text { CKD } \\
\text { Mean (SD) }\end{array}$ & $\begin{array}{l}\text { Non-CKD } \\
\text { Mean (SD) }\end{array}$ & $\begin{array}{l}\mathrm{p} \\
\text { value }\end{array}$ \\
\hline No of pts. & 380 & 570 & - \\
\hline Age(years) & $57.2(10.7)$ & $54.1(10)$ & 0.00 \\
\hline BMI (kg/m2) & $23.77(3.24)$ & $26.25(4.5)$ & 0.00 \\
\hline $\begin{array}{l}\text { Type of CAD } \\
\text { (ACS) }\end{array}$ & 182 & 285 & 0.6 \\
\hline DM & 251 & 309 & 0.00 \\
\hline Hemoglobin(g/dl) & $11.07(1.025)$ & $14.20(1.49)$ & 0.00 \\
\hline $\begin{array}{l}\text { Total cholesterol } \\
\text { (mg/dl) }\end{array}$ & $151.74(30.9)$ & $168.5(40.29)$ & 0.09 \\
\hline $\begin{array}{l}\text { Sys. BP (mmHg) } \\
\text { SPm }\end{array}$ & $158.4(26.03)$ & $158.26(29.04)$ & 0.93 \\
\hline
\end{tabular}

Table 3: Details of coronary lesions

\begin{tabular}{|l|l|l|}
\hline Vessel treated & CKD & Non CKD \\
\hline LAD \&D1 & 194 & 330 \\
\hline LCX \& OM & 110 & 162 \\
\hline RCA \& PDA & 180 & 234 \\
\hline LIMA - LAD & 3 & 5 \\
\hline LMCA & 2 & 4 \\
\hline SVG & 9 & 10 \\
\hline TOTAL & 498 & 745 \\
\hline
\end{tabular}

Table 4: Details of route of PCI and GP2b3a inhibitor usage :

\begin{tabular}{|l|l|l|l|}
\hline Variables & CKD & NON -CKD & p value \\
\hline $\begin{array}{l}\text { Multi vessel } \\
\text { angioplasty }\end{array}$ & 95 & 184 & 0.02 \\
\hline No of lesions & 477 & 766 & 0.2 \\
\hline Radial & 193 & 335 & 0.02 \\
\hline GPI received & 102 & 140 & 0.5 \\
\hline
\end{tabular}

Vascular complications were seen in 28 out of 380 patients with CKD $(7.37 \%)$ and 17 out of 570 patients without CKD (2.98\%). After the adjustment of confounding factors like route of PCI, analysis by Chisquare, patients with CKD were found to have higher 
risk of vascular complications post PCI [ $(\mathrm{p}=0.02), \mathrm{OR}=$ 2.592 (95\% CI - 1.346-5.026), RR $=2.475(95 \%$ CI - $1.327-$ 4.667)] and the result was found to be statistically significant. Further analysis of vascular complications with chi-square when evaluated as access site (hematoma and pseudo aneurysm at access site) vs nonaccess site (retroperitoneal and other site bleeds) complication, CKD was associated with non-access site complications $(\mathrm{p}=0.01)$, but not for access site complication $(p=0.06)$ as shown in Table 5.

Table 5: Vascular complications in patients who underwent PCI:

\begin{tabular}{|c|c|c|c|c|c|}
\hline Variables & CKD & $\begin{array}{l}\text { Non- } \\
\text { CKD }\end{array}$ & $\begin{array}{l}\mathrm{p} \\
\text { value }\end{array}$ & $\begin{array}{l}\mathrm{OR} \\
(95 \% \\
\mathrm{CI})\end{array}$ & $\begin{array}{l}\mathrm{RR} \\
(95 \% \\
\mathrm{CI})\end{array}$ \\
\hline $\begin{array}{l}\text { Vascular } \\
\text { complications } \\
\text { occurred }\end{array}$ & 28 & 17 & \multirow[t]{2}{*}{0.02} & \multirow{2}{*}{$\begin{array}{l}2.592 \\
(1.346 \\
\text { to } \\
5.026)\end{array}$} & \multirow{2}{*}{$\begin{array}{l}2.475 \\
(1.327 \\
\text { to } \\
4.667)\end{array}$} \\
\hline $\begin{array}{l}\text { Vascular } \\
\text { complications } \\
\text { not occurred }\end{array}$ & 352 & 554 & & & \\
\hline $\begin{array}{l}\text { Access site } \\
\text { complications }\end{array}$ & 12 & 8 & 0.06 & $\begin{array}{l}2.357 \\
(0.888 \\
\text { to } \\
6.327)\end{array}$ & $\begin{array}{l}2.312 \\
(0.89 \\
\text { to } \\
6.136)\end{array}$ \\
\hline $\begin{array}{l}\text { Non access } \\
\text { site } \\
\text { complications }\end{array}$ & 16 & 9 & 0.01 & $\begin{array}{l}2.793 \\
(1.15 \\
\text { to } \\
6.916) \\
\end{array}$ & $\begin{array}{l}2.715 \\
(1.146 \\
\text { to } \\
6.59)\end{array}$ \\
\hline
\end{tabular}

Sub group analysis was done for route of PCI. 419 patients underwent PCI through femoral route and 531 patients through radial route. There was no bleeding in 396 patients in femoral and 509 patients in radial group. Hematoma developed in 8 patients in femoral and 8 patients in radial subgroup. Retroperitoneal hematoma developed in 4 patients in femoral and 4 patients in radial subgroup. Pseudoaneurysm was seen in 6 patients in femoral group only. other bleeding complications were noted in 5 patients in femoral and 10 patients in radial subgroup.

The details of bleeding complications were given in Table 6. Regression analysis showed that for different types of vascular complications, hypertension $(\mathrm{p}=0.002)$, basal hemoglobin levels $(\mathrm{p}=0.002)$ and eGFR $(\mathrm{p}=0.01)$ are dependent factors, but not the type of CAD, DM, single or multi vessel $\mathrm{PCI}$ or route of PCI.

Fig 4 : Graph showing the distribution of variables in each study group.

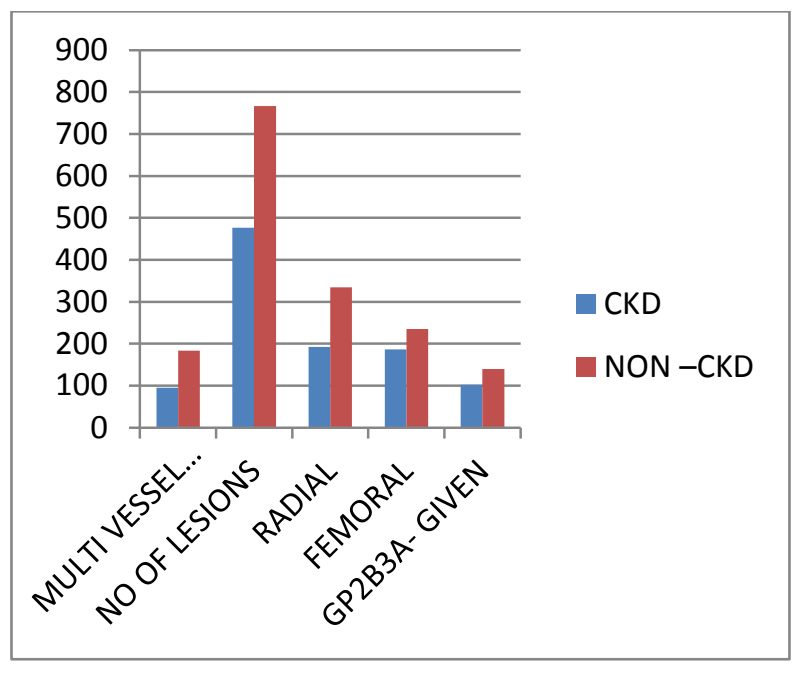

Table 6: showing non-access site (bleeding) complications according to BARC definition for bleeding13 in CKD and non-CKD group.

\begin{tabular}{|c|c|c|}
\hline Type of BARC Bleeding & CKD & Non-CKD \\
\hline 1 & 0 & 0 \\
\hline 2 & 6 & 3 \\
\hline $3 \mathrm{a}$ & 7 & 5 \\
\hline $3 \mathrm{~b}$ & 2 & 1 \\
\hline 4 & 0 & 0 \\
\hline 5 & 1 & 0 \\
\hline total & 16 & 9 \\
\hline
\end{tabular}

But in our study in basal status itself there was difference in presence of DM, single or multi vessel $\mathrm{PCI}$, route of PCI in cases of CKD vs NON-CKD, which is a limitation in the interpretation of this nominal regression analysis. After removal of variables which had already statistical difference, then after running nominal regression for occurrence of different types of vascular complications, hypertension, basal hemoglobin and eGFR were found to be dependent factors.

\section{DISCUSSION:}

Previous studies have found a strong association between impaired kidney function and bleeding 
complications following PCI [6,7]. Several mechanisms can explain this observation. Patients with CKD have uremia which itself causes platelet and endothelial dysfunction. Platelet count is usually within the normal range or slightly low in patients with uremia. It has been suggested that these patients have a complex platelet dysfunction and an abnormal platelet-endothelial vessel wall interaction. Radioligand studies have indicated that the binding of fibrinogen to ADP-stimulated platelets in uremic media is impaired. Notably, the ability of the vessel wall to generate the potent anti-aggregatory substance prostacyclin (prostaglandin $\mathrm{I}_{2}$ ) increases in uremia; moreover, endothelial cells seem to generate an abnormal complex of coagulation factor VIII (antihemophilic factor) and Von Willebrand factor (vWF). Finally, the largest polymers of $\mathrm{vWF}$, which are primarily responsible for the adhesion process, are deficient in patients with uremia, although the serum level of vWF in these patients is usually high or within the normal range.

TRA was associated with reduced access site complications[8]. In our study lesser number of CKD patients underwent PCI through TRA compared with femoral access. Though vascular complications were higher in CKD group, these were mainly non-access site bleeds, suggesting femoral route is not predisposing factors for vascular complications in CKD patients. Retroperitoneal bleed is considered as complication of femoral access site, but in our series we have seen this complication even in radial routes. So, all retro-pertonial bleeds may not be due to access site complication. CKD patients have platelet and endothelial dysfunction which could have probably led to this observation. Reduced access site complications in spite of increased femoral access site PCI in CKD group could have been due to the reason that ours being a high volume center which may have a direct bearing on the procedural outcome.

Patients in CKD group are aged compared to non-CKD group .Increased vascular complications are known to occur in elderly[9,10]. age has been identified as an independent risk factor for bleeding in patients undergoing PCI[11]. The higher incidence of bleeding and other procedural outcomes after PCI in the elderly may be due to the higher incidence of comorbidities, including more extensive atherosclerosis, hypertension and renal insufficiency, as well as their more frequent presentation with hemodynamic instability or shock and the more frequent usage of femoral arterial access[12]
Aged patients have more friable vasculature resulting in more subcutaneous oozing.

Patients in CKD group are much smaller (lesser BMI) compared to the non-CKD group. Increase in adipose tissue helps in hemostasis which when decreased could have accounted for increase in hematoma formation post PCI. Cox et al.[13] found that patients with low BMI had twice the rate of bleeding compared with obese patients in a cohort of $>5000$ patients undergoing cardiac catheterization and PCI. Similarly, Ellis et al[14] reported a higher rate of blood transfusions in patients with a low BMI $(<25 \mathrm{~kg} / \mathrm{m} 2)$ compared with those with normal or high BMI in a cohort of patients presenting with ACS. Gurm et al[15] pooled data from 4 GPI trials and found that patients with low BMI had significantly higher rates of death, MI, and bleeding. In present study the BMI of the study population is in normal range $(23.77 \pm 3.24)$.

The CCRPT (cardiac catheterization risk predictor tool) proposed by Sedlacek and Newsom considers emergent PCI as a risk predictor for vascular complications[16] but in our study there was no significant difference in outcome between patients with ACS or CSA. Multivessel PCI is associated with increased procedural time, fluoroscopy time ,use of larger size catheter and increased contrast dose. In our study larger number of non CKD patients underwent multivessel angioplasty but complication rate was less in this group compared to CKD group.

STUDY LIMITATIONS: There were few differences in baseline characteristics like age, BMI, diabetes, hemoglobin levels between the two study groups because the study design was retrospective and this might have contributed to the observations noted. CKD staging could have thrown light into the stage specific risks associated in CKD patients. Procedural and fluoroscopy time was not routinely noted which might vary in multivessel PCI. The basal difference noted in our study in the presence of DM, single or multi vessel $\mathrm{PCI}$, route of PCI was a limitation in the interpretation of nominal regression analysis.

CONCLUSIONS: Our study highlights the importance of identifying CKD patients during PCI as they are found to be at a higher risk of post PCI vascular complications. The mechanisms behind this are multifactorial. Future studies should continue to evaluate this risk as common risk factors determine both CKD and vascular disease. 


\section{REFERENCES:}

1. Gupta R,Birnbaum Y, Uretsky B. The renal patient with coronary artery disease. J Am Coll Cardiol.2004; 44:1343-1353.

2. Ted Parris. PCI in CKD: A-OK???. J Invasive Cardiol. 2007 Aug;19(8):338.

3. Cai Q,Mukku VK,Ahmad M. Coronary artery disease in patients with chronic kidney disease: a clinical update. Curr Cardiol Rev.2013 Nov;9(4):331-9.

4. K/DOQI clinical practice guidelines for chronic kidney disease: evaluation, classification, and stratification. Am J Kidney Dis. 2002;39:S1-266.5.

5. Bleeding Academic Research Consortium Definition For Bleeding.Circulation.June14,2011 vol.123 no 23 2736-2737.

6. Doyle BJ, Ting HH, Bell MR, Lennon RJ, Mathew V, Singh M, et al. Major femoral bleeding complications after percutaneous coronary intervention: incidence, predictors, and impact on long-term survival among 17,901 patients treated at the Mayo Clinic from 1994 to 2005. JACC CardiovascInterv.2008; 1:202-9.

7. Sadeghi HM, Stone GW, Grines CL, Mehran R, Dixon SR, Lansky AJ, et al. Impact of renal insufficiency in patients undergoing primary angioplasty for acute myocardial infarction. Circulation.2003; 108:2769-75.

8. Mamas MA, Anderson SG, Carr M, et al. Baseline Bleeding Risk and Arterial Access Site Practice in Relation to Procedural Outcomes After Percutaneous Coronary Intervention J Am Coll Cardiol.2014;64:1554-1564.

9. Krishnaraj Rathod,Charles Knight .Percutaneous access interventions in old age-effective or intrusive? .Br J Cardiol.2013;20:6-7.
10. Shanmugam VB, et al. PCI in octogenarians.An overview of PCI in the very elderly. J Geriatr Cardiol 2015; 12: 174-184

11. Moscucci M, Fox KA, Cannon $\mathrm{CP}$, et al. Predictors of major bleeding in acute coronary syndromes: the Global Registry of Acute Coronary Events (GRACE). Eur Heart J 2003; 24: 1815-1823.

12. Feldman DN, Gade CL, Slotwinder AJ et al. Comparison of outcomes of percutaneous coronary interventions in patients of three age groups ( $<60,60-80$, and $>80$ years). Am J Cardiol 2006; 98: 1334-1339

13. Cox N,Resnic FS,,Popma JJ,,Simon

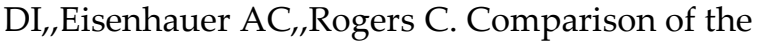
risk of vascular complications associated with femoral and radial access coronary catheterization procedures in obese versus non obese patients. Am J Cardiol. 2004;94:1174-1177.

14. Ellis SG, Elliott J, Horrigan M, Raymond RE, Howell G. Low-normal or excessive body mass index: newly identified and powerful risk factors for death and other complications with percutaneous coronary intervention. Am J Cardiol.1996;78:642-6.

15. Gurm HS,Brennan DM,Booth J,Tcheng JE,Lincoff AM,Topol EJ. Impact of body mass index on outcome after percutaneous coronary intervention (the obesity paradox). Am J Cardiol. 2002;90:42-45.

16. Sedlacek MA, Newsome J. Identification of vascular bleeding complications after cardiac catheterization through development and implementation of a cardiac catheterization risk predictor tool. 2010 May-Jun; 29(3): 145-152. 